\title{
Synaptogenesis Regulates Axotomy-Induced Activation of c-Jun-Activator Protein-1 Transcription
}

\author{
Ying-Ju Sung, ${ }^{1}$ Fang Wu, ${ }^{2}$ Samuel Schacher, ${ }^{2}$ and Richard T. Ambron ${ }^{1}$ \\ ${ }^{1}$ Department of Anatomy and Cell Biology and ${ }^{2}$ Center for Neurobiology and Behavior, New York State Psychiatric Institute, Columbia University College of \\ Physicians and Surgeons, New York, New York 10032
}

The activator protein-1 (AP1) transcription complex remains active for long periods after axotomy, but its activity diminishes during target contact. This raises the possibility that the function of this complex is regulated by the synaptic connections. Using Aplysia californica, we found that crushing peripheral nerves in vivo enhanced AP1 binding in the sensory neurons that lasted for weeks and then declined as regeneration was completed. The AP1 complex in Aplysia is a c-Jun homodimer. Its activation, after axotomy, is mediated by Aplysia c-Jun-N-terminal kinase (apJNK), which enters the nucleus of sensory neurons and phosphorylates c-Jun at Ser-73 (p73-c-Jun). Active AP1 in the sensory neurons did not mediate apoptosis and was not involved in the appearance of the long-term hyperexcitability that develops in these cells after axotomy, and blocking the activation of apJNK in vitro did not influence neurite outgrowth. In contrast, the levels of activated apJNK and p73-c-Jun declined markedly when sensory neurons formed synapses with motor neuron L7 in vitro. Furthermore, inhibiting the pathway accelerated synaptogenesis between sensory neurons and L7. These data suggest that positive and negative modulation of the JNK- c-Jun-AP1 pathway functions in alerting the nucleus to the loss and gain of synapses, respectively.

Key words: nerve injury; signal transduction pathway; regeneration; synapse formation; sensory neurons; synaptic plasticity

\section{Introduction}

Axotomy initiates changes in gene expression that either results in programmed cell death or promotes and sustains axon growth and other concomitants of regeneration. Once contact with a target has been reestablished, regeneration-specific transcription is generally downregulated to a basal state (Ambron and Walters, 1996). These alterations, in response to events in the periphery, require complex signaling cascades to the nucleus and precisely integrated control of specific transcription factors (Ambron and Walters, 1996; Tanaka et al., 1998; Sung et al., 2001; Zimmermann, 2001). To begin to understand how injury and targetderived signals regulate transcription, we examined the well characterized activator protein-1 (AP1) transcription complex comprising the Fos/activating transcription factor (ATF) and the Jun subfamilies of basic-region leucine-zipper proteins (Shaulian and Karin, 2002). These factors form homodimeric or heterodimeric complexes that bind to 12-0-tetradecanoyl-phorbol13 -acetate (TPA) response element (TRE) or cAMP response element (CRE) consensus sequences (Herdegen and Leah, 1998; Chinenov and Kerppola, 2001). Dimer formation, DNA binding, and the ability to trans-activate genes are all influenced by phosphorylation. Thus, transcriptional activation by c-Jun is strongly promoted when Ser-73 and, to a lesser extent, Ser-63 (Pulverer et

Received 0ct. 17, 2005; accepted May 2, 2006.

This work was supported by Javits National Institutes of Health Grant NS 22150 and National Institutes of Health Grant NS 42159. We extend our thanks to Drs. M. Karin for the pGEXC-Jun(1-79) construct, B. K. Kaang for the pNEX3-GFP and pNEXAP1-GFP constructs, and R. B. Denman for his comments on this manuscript.

Correspondence should be addressed to Ying-Ju Sung, Department of Anatomy and Cell Biology, Columbia University College of Physicians and Surgeons, 630 West 168th Street, New York, NY 10032. E-mail: yjs8@columbia.edu.

D0I:10.1523/JNEUROSCI.1844-06.2006

Copyright $\odot 2006$ Society for Neuroscience $\quad$ 0270-6474/06/266439-11\$15.00/0 al., 1991; Smeal et al., 1991, 1994) are phosphorylated by Jun N-terminal kinases (JNKs) (Hibi et al., 1993; Derijard et al., 1994; Kallunki et al., 1994; Kyriakis et al., 1994).

JNK is a positive injury signal in the rat sciatic nerve (Lindwall and Kanje, 2005), i.e., it is activated by axotomy and transported retrogradely to the cell body in which it phosphorylates c-Jun. The resultant c-Jun AP1 transcription complex then persists for weeks (Kenney and Kocsis, 1998), suggesting an important role in the regeneration process and one that presumably diminishes when target contact is reestablished. Many functions have been ascribed to the injury-activated AP1, some of which are contradictory (Karin et al., 1997; Herdegen and Leah, 1998; Herdegen and Waetzig, 2001; Waetzig and Herdegen, 2004). The multifunctional property of AP1 complexes may arise from its activation by a variety of noxious stimuli other than nerve injury and by variable composition that depends on the neuron type. The observation that AP1 activity persists for weeks after axotomy of rat primary sensory neurons (Kenney and Kocsis, 1998) suggested that sensory neurons might be good models to study the longterm role of the AP1. We used the experimentally favorable bilateral cluster of pleural sensory neurons of Aplysia that respond to noxious stimuli from the body wall (Sung et al., 2004). We systematically studied AP1 activation by Aplysia JNK (apJNK), from the time of axotomy through regeneration to the reestablishment of synaptic contact. We found that this pathway does not govern growth, apoptosis, or changes in excitability but strongly and precisely responds to interactions with postsynaptic neurons during the formation of synapses.

\section{Materials and Methods}

Surgical procedure. Aplysia (100-150 g) were anesthetized with isotonic $\mathrm{MgCl}_{2}$, and a small incision was made on one side of the body wall. Pedal 
nerves 5-9 were crushed $2 \mathrm{~cm}$ from the pedal-pleural ganglia on one side. The wound was sutured, and the animal was returned to its tank.

Electrophoretic mobility shift assays. Protein samples were incubated with a ${ }^{32} \mathrm{P}$-double-stranded TRE oligonucleotide (Santa Cruz Biotechnology, Santa Cruz, CA) for $20 \mathrm{~min}$ at room temperature in $10 \mathrm{~mm}$ Tris-HCl, pH 7.5, 50 mм NaCl, 1 mм $\mathrm{MgCl}_{2}, 0.5$ mм EDTA, 0.5 mм DTT, $50 \mu \mathrm{g} / \mu \mathrm{l}$ poly $(\mathrm{dI}-\mathrm{dC})$, and $4 \%$ glycerol. Each reaction mixture contained either $10 \mu \mathrm{g}$ of protein from a neuronal extract or $3 \mu \mathrm{g}$ from nuclear extract, plus $35 \mathrm{nmol}(20,000-50,000 \mathrm{cpm})$ of labeled oligonucleotide in a total volume of 10-20 $\mu$ l. Protein-DNA complexes were separated on nondenaturing $4 \%$ polyacrylamide gels at room temperature in $0.5 \times$ Tris borate-EDTA buffer. The gels were dried and subjected to autoradiography. Competition was determined by adding a 25-fold molar excess of an unlabeled double-stranded oligonucleotide [TRE, mutant TPA response element (TREM), CRE, and enhancer response element (ERE)] to the binding reaction. For supershift analyses, 2-3 $\mu$ l of an antibody (Ab) was added to the extracts $1 \mathrm{~h}$ before adding the labeled oligonucleotides.

Cloning. Degenerate oligonucleotide primers (5'-atggaygcnaayytntgycarg and $5^{\prime}$-tartanckngtnacnacrtangg) were used to amplify an apJNK cDNA fragment from Aplysia CNS cDNA. The resulting amplicon was cloned and then sequenced. The $5^{\prime}$ end and $3^{\prime}$ end of the cDNA were cloned separately using $5^{\prime}$ rapid amplification of cDNA ends (RACE) (5' -aggtaggacatgcgctcatggt) and 3' RACE (5'-atgatgacgccgtacgtggtgact). To obtain the full-length cDNA another PCR was performed with primers corresponding to the $5^{\prime}$ and $3^{\prime}$ ends of $5^{\prime}$ and $3^{\prime}$ RACE products, respectively. This product was sequenced and designated apJNK; it was deposited in GenBank under accession number AY263405.

Plasmid. A histidine (His) tag was added to the $\mathrm{N}$ terminus of the apJNK-coding region by PCR amplification from Aplysia CNS cDNA with primers $5^{\prime}$-cgttgcggecgcaccatgggacatcaccatcaccatcacaacaagctattaagtc and $5^{\prime}$-ggaatctagagtggtggttctgcgc. The PCR product was subcloned into the NotI and XhoI sites of pcDNA3.1/C-terminal-green fluorescent protein (GFP) (Invitrogen, Carlsbad, CA) and was subsequently confirmed by sequencing. The resulting construct contains a GFP tag at the $\mathrm{C}$ terminus.

Protein expression and purification. Full-length ${ }^{35} \mathrm{~S}-\mathrm{His}-\mathrm{apJNK}-\mathrm{GFP}$ was produced by in vitro transcription translation as described previously (Sung et al., 2000) and was purified on nickel-nitrilotriacetic acid resin (Sung et al., 2004). Recombinant glutathione S-transferase (GST)-c-Jun (1-79) was prepared as described previously (Lin et al., 1995).

Western blotting and immunocytochemistry. Protein samples were resolved by SDS-PAGE and subsequently blotted onto nitrocellulose; blots were probed with gene-specific antibodies as described previously (Sung et al., 2004). For immunostaining, pleural ganglia or cultured neurons were fixed with $4 \%$ paraformaldehyde and subsequently probed with various antibodies as described previously (Sung et al., 2004). The cells were then visualized by confocal fluorescence microscopy.

In vitro kinase assay. JNK activity was assayed as described previously (Sung et al., 2001). Briefly, active His-apJNK-GFP recombinant protein $(0.1 \mu \mathrm{g})$ or neuronal extract $(5 \mu \mathrm{g})$ was incubated with $0.5 \mu \mathrm{g}$ of GSTc-Jun (1-79) or $25 \mu \mathrm{g}$ of pleural neuronal extract and $10 \mu \mathrm{M}\left[\gamma^{-32} \mathrm{P}\right] \mathrm{ATP}$ or $100 \mu \mathrm{M}$ ATP in kinase buffer as described previously (Sung et al., 2004). The reaction mixture was resolved by SDS-PAGE and subjected to autoradiography or Western blotting.

MTT assay. The MTT assay (Mossman, 1983) was used to quantify neuron viability after axotomy. The injured and contralateral uninjured pleural ganglia were collected, desheathed, and incubated in $0.2 \mathrm{mg} / \mathrm{ml}$ MTT (Sigma, St. Louis, MO) dissolved in modified L- 15 culture medium without phenol red. After incubating at $15^{\circ} \mathrm{C}$ for $4 \mathrm{~h}$, the reaction solution was aspirated, and $0.5 \mathrm{ml}$ of acidified isopropyl alcohol (2-propanol- $0.08 \mathrm{~N} \mathrm{HCl}$ ) was added to each sample to dissolve the formazan crystals; the samples were shaken on a rotary shaker for 15-20 min. Aliquots of $150 \mu \mathrm{l}$ were then transferred to a 96-well microtiter plate and mixed with $150 \mu \mathrm{l}$ of acidified isopropyl alcohol. The absorbance was recorded at $570 \mathrm{~nm}$ with a reference wavelength of $630 \mathrm{~nm}$ in a microtiter plate reader (Titertek Multiskan MCC/340; Flow Laboratories, Baar, Switzerland). The optical density of acidified isopropyl alcohol was sub- tracted as background. All values were normalized to control ganglia collected from animals without nerve crush.

Terminal deoxynucleotidyl transferase-mediated biotinylated UTP nick end labeling assay. The in situ cell death detection kit (Roche, Indianapolis, IN) was used according to the instructions of the manufacturer. Briefly, frozen tissue sections were fixed with $4 \%$ paraformaldehyde in PBS, $\mathrm{pH} 7.4$, for $1 \mathrm{~h}$ at room temperature and then permeabilized with $0.1 \%$ Triton X-100 in $0.1 \%$ sodium citrate for $5 \mathrm{~min}$ on ice. DNA breaks were labeled by adding terminal deoxynucleotidyl transferase and a nucleotide mixture containing fluorescein isothiocyanate-conjugated dUTP and incubating for $60 \mathrm{~min}$ at $37^{\circ} \mathrm{C}$. Tissues were washed extensively with PBS and then analyzed by fluorescence microscopy.

Cell culture. Sensory neurons were isolated from the pleural ganglia of 50-80 g animals and the abdominal ganglia of 1.5-3 g animals, respectively, and were plated on poly-L-lysine-coated dishes containing L-15 medium and 50\% hemolymph (Rayport and Schacher, 1986). Sensorymotor cocultures were prepared from Aplysia as described previously (Montarolo et al., 1986; Rayport and Schacher, 1986; Martin et al., 1997; Schacher et al., 1999). Sensory neurons were removed from the pleural ganglia after $2 \mathrm{~h}$ of digestion and were plated such that their terminal processes came into contact with the initial segment of an L7 or L11 motor neuron. For axotomy in vitro, the major neurites of each neuron were transected with a glass microneedle as described previously (Ambron et al., 1996). In some experiments, the JNK inhibitor SP600125 (1,9-pyrazoloanthrone) or its inactive form [ $\left[N^{1}\right.$-methyl-1,9pyrazoloanthrone $(\mathrm{NmP})$ ] (Calbiochem, San Diego, CA) was added to the medium (final concentration, $1 \mu \mathrm{M}$ ) $0.5-1 \mathrm{~h}$ before axotomy.

Measurement of neurite outgrowth. Each cell image was captured with Argus 20 video camera immediately after axotomy and then on the following day. Neurite length was determined in Adobe Photoshop (Adobe Systems, San Jose, CA) using the measuring tool and an overlay of the cell before and after the axotomy. Growth is defined as the net increase in neurite length $24 \mathrm{~h}$ after axotomy.

Electrophysiology. Before the start of each recording, the hemolymph was replaced with a 1:1 mixture of artificial seawater and culture medium (without hemolymph, pH 7.6). Standard techniques were used for intracellular stimulation and recording (Ambron et al., 1996). The soma spike threshold was measured with a standard series of $20 \mathrm{~ms}$ depolarizing pulses. Repetitive firing was quantified by counting the number of spikes evoked by a series of $2 \mathrm{~s}$ depolarizing pulses at 1, 2, 3, 4, and $5 \mathrm{nA}$ (Sung et al., 2004). EPSPs were measured in sensory-motor cocultures as described previously (Montarolo et al., 1986; Dale et al., 1988). Briefly, the L7 motor neuron was impaled and the membrane potential was held at $-85 \mathrm{mV}$. The EPSPs were evoked in L7 by extracellular stimulation of the sensory neurons with a brief depolarizing stimulus $(0.3-0.5 \mathrm{~ms})$ to evoke an action potential.

Microinjection. DNA constructs $(0.75 \mu \mathrm{g} / \mu \mathrm{l}$ in $10 \mathrm{~mm}$ Tris- $\mathrm{HCl}, \mathrm{pH}$ $7.3,100 \mathrm{~mm} \mathrm{NaCl}$, and $0.05 \%$ fast green dye) were microinjected into cultured sensory neurons by positive pressure under defined conditions as described previously (Sung et al., 2001).

Antibodies. All of the antibodies used here were raised against vertebrate antigens. c-Jun $(\mathrm{N})$ (recognizes the $\mathrm{N}$-terminal domain of c-Jun p39), c-Jun(D) (recognizes the DNA binding domain of c-Jun p39), c-Fos(4) (recognizes the $\mathrm{N}$ terminus of c-Fos), Rel (recognizes the $\mathrm{N}$ terminus of c-Rel p75), and JunD (recognizes the C terminus of JunD) were obtained from Santa Cruz Biotechnology. Antibodies to phosphorylated JNK (p-JNK) (recognizes the dually phosphorylated form of JNK1/2/3), Ser-73 (p73-c-Jun) and its blocking peptide, and an antibody to ATF-2 phosphorylated on Thr-69/71 (p-ATF-2) were obtained from Cell Signaling Technology (Beverly, MA).

\section{Results}

\section{Axotomy induces long-term AP1 DNA binding mediated by JNK phosphorylation of c-Jun}

To determine whether the AP1 transcription complex plays a role in regulating gene expression after axotomy, we followed changes after nerve injury in vivo. Aplysia peripheral nerves p5-p9 on one side were crushed through a small incision in the body wall, 
$\mathbf{A}$

B
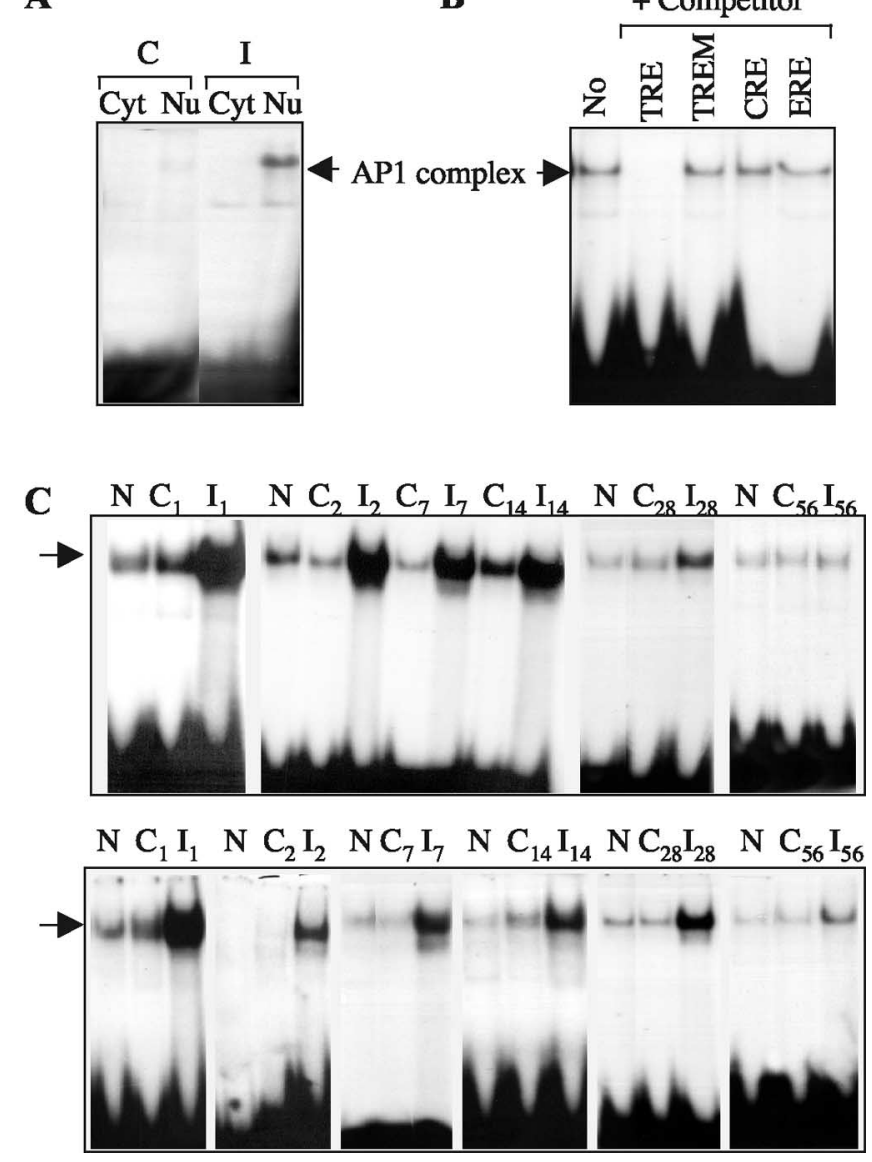

Figure 1. A, Formation of an AP1 complex in nuclei from neurons after nerve injury. At $24 \mathrm{~h}$ after crushing the pedal nerves, cytosolic (Cyt) and nuclear ( $\mathrm{Nu}$ ) extracts from injured (I) and contralateral (C) pleural neurons were assayed for binding to a ${ }^{32} \mathrm{P}$-labeled TRE oligonucleotide via EMSA. $\boldsymbol{B}$, The specificity of AP1 activation was verified by competition of the ${ }^{32} \mathrm{P}$-labeled TRE oligonucleotide with a nonradioactive TRE, TREM, CRE, or ERE oligonucleotide cassette. C, Time course of AP1 DNA binding. At the indicated times (days) after nerve crush, extracts collected from uninjured (N), injured (I), and contralateral (C) pleural ganglion neurons were assayed for AP1 binding as in $\boldsymbol{A}$. Neurons from four animals were combined for each time point. Representative results of AP1 binding for duplicate times from different sets of pooled neurons are shown. The AP1 complex is marked by arrows.

thereby axotomizing most of the sensory neurons in the pleural ganglion (Steffensen et al., 1995). The incision was sutured, and, $24 \mathrm{~h}$ later, we removed the neurons from the ipsilateral and contralateral pleural ganglia and prepared extracts of the cell nuclei and cytoplasm. Samples were incubated with a canonical ${ }^{32} \mathrm{P}-$ labeled TRE oligonucleotide sequence from the AP1 enhancer site, and binding was assessed by electrophoretic mobility shift assay (EMSA) (Fig. 1A). A single retarded AP1 binding complex was markedly enhanced in the injured neurons relative to the controls, and all of the binding activity was in the nuclear fraction (Fig. 1A). The binding was specific because excess unlabeled TRE oligonucleotide competed for the radiolabeled probe, whereas an equivalent amount of unlabeled CRE, ERE, or TREM oligonucleotide had no effect (Fig. $1 B$ ). Because the DNA binding was confined to the nucleus, subsequent analyses were performed with cell homogenates.

Some transcription factors respond to axotomy in phases with a prominent later phase mediated by a positive injury signal (Lin et al., 2003; Sung and Ambron, 2004). We examined the time course of AP1 activation in pleural neurons and found that, from
$24 \mathrm{~h}$ after injury to 4 weeks after injury, there was a threefold increase in AP1 binding in extracts from injured versus uninjured animals (Fig. 1C). Importantly, elevated AP1 binding was not observed in the contralateral controls of the injured animals. The binding declined by the eighth week (Fig. 1C), when the tailwithdrawal reflex had recovered and the animals could again use the tail in locomotion. This indicated that axons had contacted their targets in the periphery.

We characterized the AP1 complex by testing seven antibodies to AP1 cofactors for their ability to supershift the AP1 complex in neurons on the day 1 after nerve crush (Fig. $2 A$ ). Only the antibody to p73-c-Jun (Ab-p73-c-Jun) and that to c-Jun/AP1(N) (Ab-c-JunN) supershifted the complex; antibodies to c-Fos, JunD, p-ATF-2, and Rel had no effect, although each antibody recognized an appropriate size band on Western blots of injured and uninjured neuronal extracts (data not shown).

When we examined injured pleural neurons 2,7 , and $14 \mathrm{~d}$ after injury, Ab-p73-c-Jun and Ab-c-JunN supershifted the AP1 protein complex at each time (Fig. $2 B$ ). Because p73-c-Jun is active (Smeal et al., 1994), these data indicate that the AP1 complex containing c-Jun transcribes mRNA for at least 2 weeks after nerve crush.

To localize p73-c-Jun after axotomy, we crushed p5-p9 on one side and, 2 and $14 \mathrm{~d}$ later, excised sensory neuron clusters from the injured and contralateral control pleural ganglia and from pleural ganglia of animals that were not injured. Immunostaining with Ab-p73-c-Jun revealed that p73-c-Jun was expressed at very low levels in sensory neurons from uninjured animals (Fig. 2C). In contrast, staining in the nucleus of the 2 and $14 \mathrm{~d}$ injured sensory neurons was markedly enhanced relative to the contralateral controls (Fig. 2C). Preincubating the Ab-p73$\mathrm{c}$-Jun with its corresponding blocking peptide completely eliminated the p73-c-Jun nuclear staining from injured sensory neurons (Fig. 2C). These studies support the idea that transcriptioncompetent c-Jun is present in the AP1 protein complex in the sensory neurons for long periods after nerve crush. Small nonneuronal cells were also stained in both injured and uninjured ganglia at later times, perhaps as an inflammatory response (Farr et al., 2001).

Ser-73 in vertebrate c-Jun is phosphorylated by JNKs (Hibi et al., 1993; Derijard et al., 1994), and we cloned apJNK, which is highly homologous to other JNK family members (Fig. 3A). apJNK has a predicted molecular weight of $47 \mathrm{kDa}$ and contains a characteristic -T-P-Y- (threonine-proline-tyrosine) sequence. The phosphorylation of both the $\mathrm{T}$ and $\mathrm{Y}$ residues in this domain activates the kinase (Kyriakis et al., 1994) and an antibody (Ab-p-JNK) that recognizes mammalian JNK phosphorylated at both sites recognized a $48 \mathrm{kDa}$ protein in injured Aplysia neurons (Fig. 3B).

To investigate whether active apJNK phosphorylates c-Jun, we used in vitro translation to produce an ${ }^{35} \mathrm{~S}$-labeled apJNK containing a histidine tag on its $\mathrm{N}$ terminus and a GFP tag at its $\mathrm{C}$ terminus (Fig. 3C). We demonstrated that this system produces an activated kinase by showing that affinity-purified ${ }^{35} \mathrm{~S}$-HisapJNK-GFP phosphorylated recombinant GST-c-Jun(1-79) in vitro (Fig. $3 D$ ). We then added the active ${ }^{35} \mathrm{~S}$-His-apJNK-GFP to an extract of uninjured pleural-pedal neurons and found that it phosphorylated endogenous c-Jun at the site recognized by Abp73-c-Jun (Fig. 3E). Thus, axotomy activates the JNK-c-JunAP1 pathway in the sensory neurons, and the AP1 binding persists for weeks. 
$\mathbf{A}$

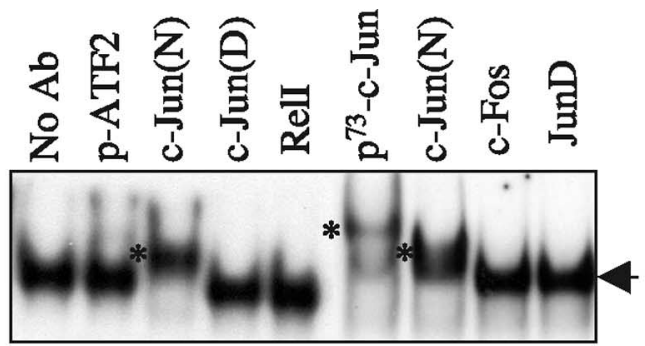

B

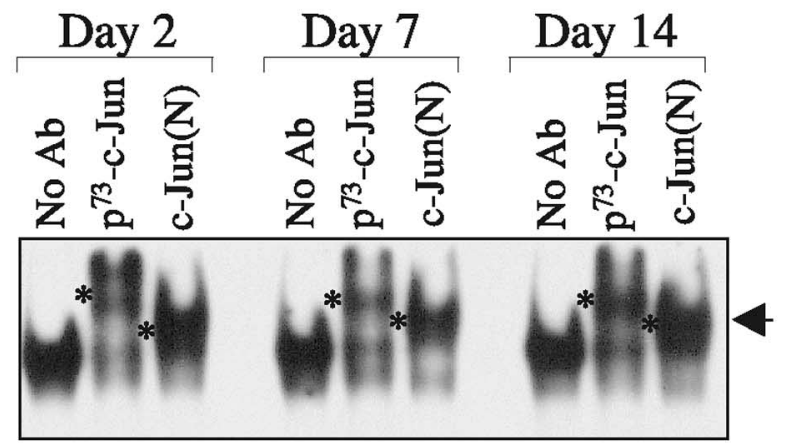

C

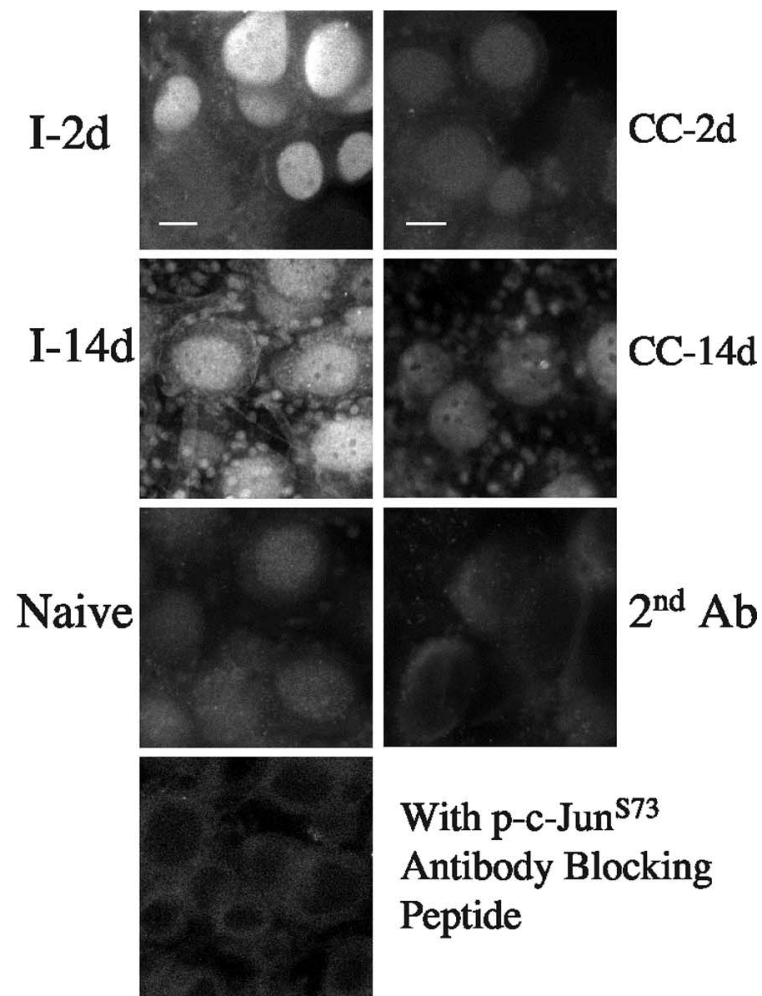

Figure 2. Characterizing the injury-induced AP1 protein complex. A, Antibodies to p73-cJun, p-ATF-2, c-Jun(N), c-Jun(D), Rel, c-Fos, and JunD were preincubated with pleural ganglion neuronal extracts (obtained $1 \mathrm{~d}$ after nerve crush) and binding to the ${ }^{32} \mathrm{P}$-labeled TRE oligonucleotide was assayed via EMSA. An asterisk denotes supershifted complexes. $\boldsymbol{B}$, Supershift assay at the indicated times after nerve crush using p73-c-Jun and c-Jun(N) antibodies as in $\boldsymbol{A}$. Neurons from four animals were combined for all of the supershift assays presented in $\boldsymbol{A}$ and $\boldsymbol{B}$. C, The level of $\mathrm{p} 73-\mathrm{c}-J u n$ is elevated in sensory neuron nuclei after nerve crush. At $2 \mathrm{~d}$ and $14 \mathrm{~d}$ after nerve crush, the sensory neuron cluster from the injured (I-2d and I-14d) and contralateral control sides (CC-2d and CC-14d) were removed and immunostained with Ab-p73-cJun. Two micrometer optical sections showing the nucleus were obtained by confocal microscopy. Staining of uninjured (Naive) neurons, background staining of a 2 dinjured sample in the absence of primary antibody (second $A b$ ), and the staining a $2 \mathrm{~d}$ injured sample in the presence of a p73-c-Jun blocking peptide are also shown. Scale bar, $50 \mu \mathrm{m}$.
$\mathbf{A}$

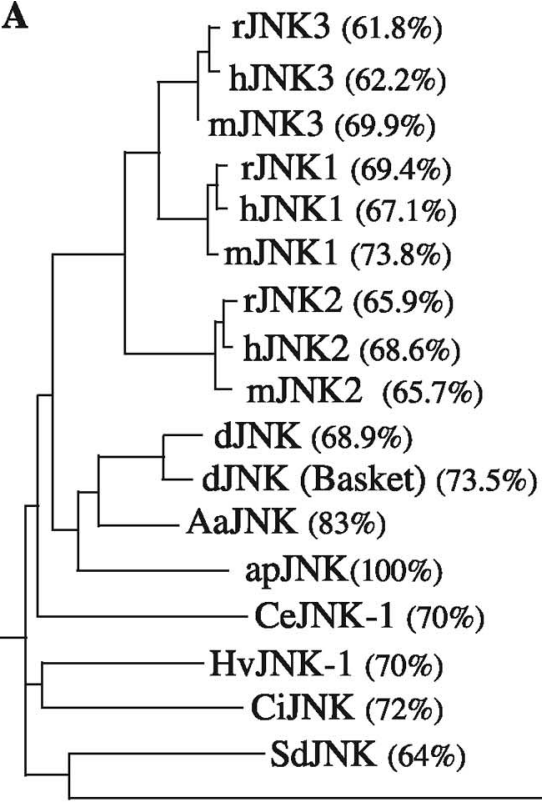

apMAPK (37\%)

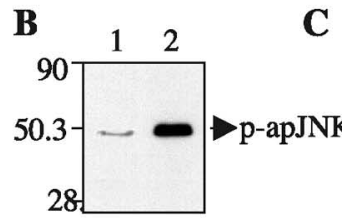

$\mathbf{C}$

D

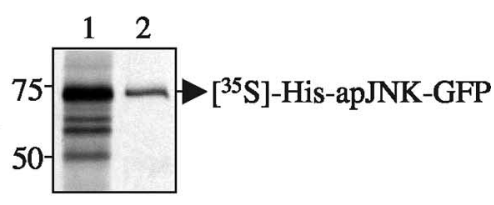

$\mathbf{E}$

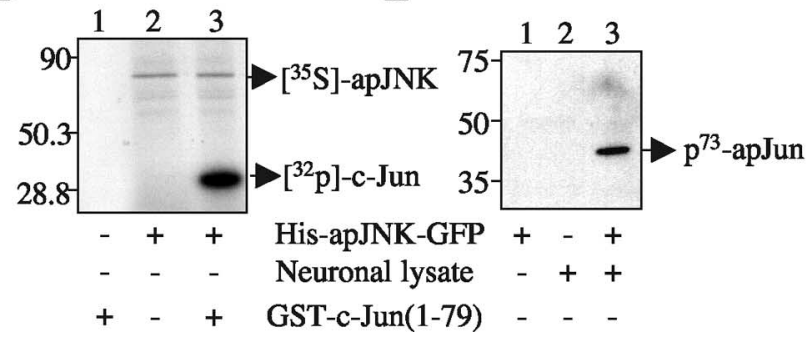

Figure 3. A, PHYLIP analysis of the JNK family. Sequence identities of Aedes albopictus AaJNK (GenBank accession number AA031950), Ciona intestinalis CiJNK (GenBank accession number BAE06525), Hydra vulgaris HvJNK (GenBank accession number AAU93351), Caenorhabditis elegans CeJNK1 (GenBank accession number NP_741434), Suberites domuncula SdJNK (GenBank accession number CAC85496), Drosophila dJNK (GenBank accession number AAC47325) and Basket (GenBank accession number P92208), human hJNK1 (GenBank accession number NP_620637), hJNK2 (GenBank accession number NP_620707) and hJNK3 (GenBank accession number P53779), rat rJNK1 (GenBank accession number P49185), rJNK2 (GenBank accession number P49186), and rJNK3 (GenBank accession number P49187), mouse mJNK1 (GenBank accession number Q91Y86), mJNK2 (GenBank accession number Q9WTU6), and mJNK3 (GenBank accession number Q61831), and Aplysia californica apMAPK (GenBank accession number AAA83210) were computed with respect to apJNK by CLUSTAL-W and PHYLIP (version 3.6) (http://workbench.sdsc.edu/); percentages are shown in parentheses. B, p-JNK antibody recognizes apJNK in neuronal lysates. Western blot of $20 \mu \mathrm{g}$ of protein extracted from contralateral uninjured (lane1) and injured (lane 2) pleural neurons $1 \mathrm{~d}$ after nerve crush was probed with Ab-p-JNK. C, Expression and purification of apJNK. Lane 1, Autoradiograph after SDS-PAGE showing the expression of ${ }^{35} \mathrm{~S}$-labeled recombinant His-apJNK-GFP produced by in vitro translation. Lane 2, The recombinant protein after affinity purification. D, Recombinant His-apJNKGFP phosphorylates a recombinant GST- - -Jun fusion protein containing the Ser-73 site. HisapJNK-GFP activity was assayed by the transfer of ${ }^{32} \mathrm{P}$ from [ $\gamma^{-}{ }^{32}$ P]ATP to GST-c-Jun (1-79) in vitro, followed by autoradiography. $\boldsymbol{E}$, Recombinant His-apJNK-GFP phosphorylates endogenous c-Jun at Ser-73 in vitro. Purified His-apJNK-GFP was added to an extract prepared from uninjured neurons, and the production of c-Jun phosphorylated at Ser-73 was assessed by probing a Western blot with Ab-p73-c-Jun. 


\section{Injury-activated AP1 does not regulate the viability, growth, or electrophysiological properties of axotomized sensory neurons}

Finding a persistent activation of the AP1 complex in pleural neurons during regeneration suggested that its function is associated with a long-term process, such as growth, rather than apoptosis. To pursue this idea, we focused on the sensory neurons and monitored their vital state after nerve crush in vivo by using two complementary methods: (1) the MTT assay, which measures cellular mitochondrial dehydrogenase activity; and (2), the terminal deoxynucleotidyl transferase-mediated biotinylated UTP nick end labeling (TUNEL) assay, which examines DNA strand breaks. The MTT assay showed that almost all of the sensory neurons were viable 4 weeks after our standard peripheral nerve injury procedure (supplemental Fig. $1 A$, available at www. jneurosci.org as supplemental material). These results were confirmed by TUNEL staining of neurons in sections from $5 \mathrm{~d}$ injured and contralateral uninjured pleural ganglia, as well as control pleural ganglia collected from animals without nerve crush (supplemental Fig. $1 B$, available at www.jneurosci.org as supplemental material). No staining was observed in the control cells in the absence of terminal deoxynucleotidyl transferase or in control cells alone (supplemental Fig. $1 B$, available at www. jneurosci.org as supplemental material). Similarly, no significant DNA strand breaks were observed in sections taken from axotomized or contralateral control neurons. The staining protocol worked because DNA strand breaks were detected in control neurons exposed to DNAse1 for $10 \mathrm{~min}$. Finally, when parallel sections containing injured and contralateral control sensory neurons were immunostained with Ab-p73-c-Jun, an enhanced level of nuclear p73-c-Jun was observed in injured sensory neurons compared with the controls (supplemental Fig. $1 C$, available at www.jneurosci.org as supplemental material). We conclude that the enhanced level of p73-c-Jun and the increase in AP1 DNA binding activity in the sensory neurons after peripheral nerve crush do not cause apoptosis.

Next we examined growth in vitro using the sensory neurons. Under our culture conditions, neurons exhibit rapid neurite growth for 3-4 d, followed by diminishing growth over the subsequent 3-4 d and cessation of growth on approximately the day 9 (Ambron et al., 1996). Immunocytochemistry on $2 \mathrm{~d}$ sensory neurons revealed prominent nuclear staining for both p-apJNK and p73-c-Jun (Fig. 4A). To determine whether the presence of p73-c-Jun in the nucleus in response to axotomy results in transcriptionally active AP1, we injected $1 \mathrm{~d}$ cultured sensory neurons with a GFP expression plasmid that harbors eight copies of the TRE enhancer site in a limited rous sarcoma virus promoter (pNEXAP1-GFP). As shown in Figure 4B, GFP was expressed $16 \mathrm{~h}$ later. No GFP was expressed in control sensory neurons injected with a GFP plasmid lacking the TRE enhancers (pNEX-GFP).

We then took advantage of a previous finding that transecting the neurites of Aplysia neurons in vitro elicits robust new growth (Ambron et al., 1996). The response of apJNK to this second axotomy was investigated by severing the neurites of some sensory neurons on day 7 in vitro; other sensory neurons in the same dish were left intact as controls. Fifteen minutes later, the neurons were fixed and exposed to Ab-p-apJNK. Strong p-apJNK staining was observed in the nucleus of the reaxotomized sensory neurons (Fig. 4C, bottom). There was a relatively low level of p-apJNK immunostaining in the nuclei of the control sensory neurons (Fig. 4C, top), which was expected because the rate of growth on day 7 is declining.
Despite the strong correlation between neurite regeneration and the increase in apJNK phosphorylation, the activation of c-Jun does not contribute to any aspect of growth. We directly demonstrated this with SP600125, which blocks JNK-mediated c-Jun phosphorylation and AP1 binding (Shin et al., 2002; Park et al., 2004). We first determined the in vitro activity of SP600125 in inhibiting c-Jun phosphorylation (Fig. 4D). Incubating injured neuronal extracts with 1 or $10 \mu \mathrm{M}$ SP600125 resulted in a 70 and 98 reduction in substrate c-Jun phosphorylation, respectively, (Fig. 4D, lanes 2, 3) relative to control samples (Fig. 4D, lane 1) assayed in the absence of SP600125. In contrast, SP600125 had no effect in inhibiting kinases such as Aplysia mitogen-activated protein kinase (apMAPK), which phosphorylates Elk1 (Lin et al., 2003) (Fig. 4D, lanes 5-7). These data demonstrate that SP600125 exhibits selective inhibitory properties against Aplysia kinases at the concentrations used (see Discussion), and we used SP600125 at a concentration of $1 \mu \mathrm{M}$ for all the following experiments.

Sensory neurons were grown in vitro and, $4 \mathrm{~d}$ later, their neurites were cut in the presence of SP600125. As a control, neurites were also cut in the presence of the inactive form of the inhibitor, $\mathrm{NmP}$. One day later, the sensory neurons were fixed and exposed to Ab-p73-c-Jun. As expected, greatly reduced levels of p73c-Jun were detected in the sensory neurons exposed to the SP600125 relative to $\mathrm{NmP}$ (Fig. $4 E$ ). These data are consistent with JNK being the primary activator of c-Jun. A person with no knowledge of the treatments then measured neurite outgrowth as the net increase in neurite length $24 \mathrm{~h}$ after axotomy in $11 \mathrm{neu}-$ rons from each population (Fig. 5). In three separate experiments, no differences were found (relative neurite outgrowth for SP600125, $289.5 \pm 51.9$ versus NmP, $299.8 \pm 63.9)$.

To further investigate the effect of SP600125, we incubated pleural ganglia in the presence of the drugs before axotomizing and placing the sensory neurons in culture and then for the subsequent $2 \mathrm{~d}$ in vitro. As above, there was no difference in the parameters of growth between cells exposed to the active and inactive forms of the drug (data not shown). These experiments show that the activity of apJNK and c-Jun are not required for growth after axotomy.

Sensory neurons develop long-term hyperexcitability (LTH) when they are axotomized in vivo (Liao et al., 1999) or placed in vitro (Bedi et al., 1998; Liao et al., 1999; Sung et al., 2004). To determine whether inhibiting apJNK activity affects the appearance of LTH, we exposed sensory neurons to SP600125 or NmP during dissociation from the ganglion and throughout the in vitro incubation. Other sensory neurons, not exposed to the drug, were removed from ganglia as controls. At $72 \mathrm{~h}$ later, we assessed hyperexcitability using a series of $2 \mathrm{~s}$ depolarizing pulses $(1,2,3$, 4 , and $5 \mathrm{nA}$ ) delivered into the cell soma (Sung et al., 2004). No significant differences were found in the excitability of the sensory neurons exposed to SP600125 or the naive controls at any current level. The maximum repetitive firing spikes for eight of each naïve-, SP600125-, and NmP-treated cells was $7.38 \pm 2.74$, $6.25 \pm 1.39$, and $7.87 \pm 2.74$, respectively. Also, there was no significant difference among the groups in membrane potential $(45.25 \pm 2.62,44.5 \pm 1.72$, and $45.22 \pm 1.49)$ or spike threshold $(1.51 \pm 0.3,1.17 \pm 0.14$, and $1.19 \pm 0.17)$.

\section{apJNK and c-Jun activities in sensory neurons are decreased} by synapse formation

The reduction in AP1 binding as regeneration in vivo nears completion (Fig. 1C) suggested that AP1 activity in the sensory neurons might be regulated by an interaction with a target. We there- 
fore removed sensory neurons and placed them in vitro either alone or in contact with motor neurons L7 or L11. Sensory neurons grown in isolation do not form chemical synapses with themselves (autapses) or with other sensory neurons, nor do they form synapses with physiological inappropriate motor neurons, such as L11 (Glanzman et al., 1989). The formation of synapses in vitro between sensory neurons and L7, but not with L11, has been studied extensively in the context of both the formation of specific synapses and learning (Rayport and Schacher, 1986; Glanzman et al., 1989, 1990; Schacher and Montarolo, 1991; Martin et al., 1997; Chin et al., 2002; Hu et al., 2004). After contacting L7, growth and the formation of varicosities by sensory neurons are significantly greater than that detected for sensory neurons cultured alone or in contact with L11 (Glanzman et al., 1989; Schacher and Montarolo, 1991). In addition, the sensory neuron synapses undergo both short- and long-lasting strengthening in response to the application of the modulatory neurotransmitter serotonin.

Four days later, when the neurites in the cocultures were intertwined (Fig. 6A), we fixed and immunostained the cells to assess the level of p73-c-Jun and p-apJNK in the nucleus of the sensory neurons (Fig. $6 B, C)$. The intensity of p73-c-Jun staining in the sensory neurons in contact with L7 was significantly less than that in the sensory neurons alone $(p<0.0001$ by ANOVA and Newman-Keuls test) and in the sensory neurons in contact with L11 ( $p=0.0017$ by ANOVA and NewmanKeuls test). Similarly, the intensity of p-apJNK staining in the nucleus of sensory neurons in contact with L7 was significantly less than that in the sensory neurons alone $(p=0.0035$ by ANOVA and Newman-Keuls test). In contrast, nuclear p-apJNK immunoreactivity was not significantly altered in sensory neurons that contacted L11 compared with sensory neurons alone $(p=0.1682)$ (Fig. $6 B, C)$. In addition, the reductions in p73-c-Jun and p-apJNK nuclear staining in sensory neuron-L7 cocultures correlate with each other $(p=0.011)$. Therefore, the activity of both apJNK and c-Jun in the nucleus of these sensory neurons is reduced during synapse formation.

Functional synaptic connections between sensory neurons and L7 are detected by $16 \mathrm{~h}$ under our culture conditions (Zhu et al., 1994; Sun and Schacher, 1996). The efficacy of the connections increases with time and reaches a stable level by $4 \mathrm{~d}$ (Glanzman et al., 1989; Zhu et al.,
$\mathbf{A}$
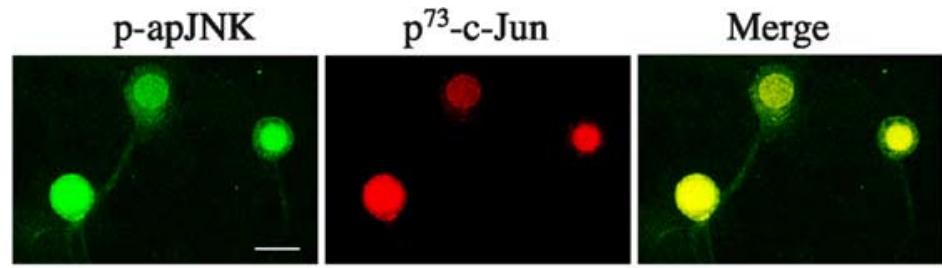

B

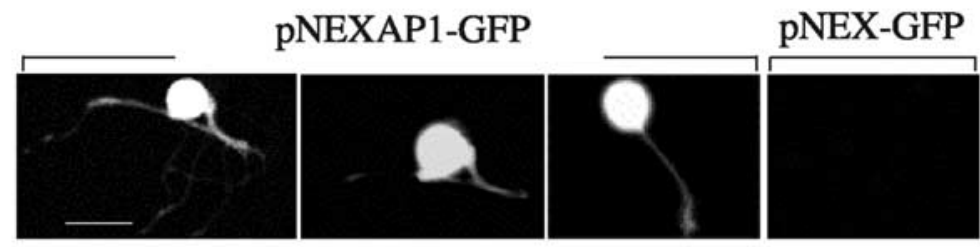

C
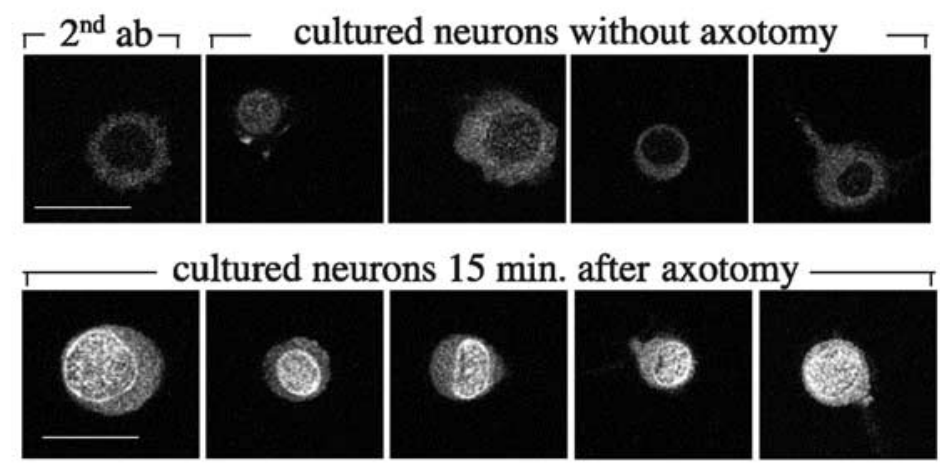

D

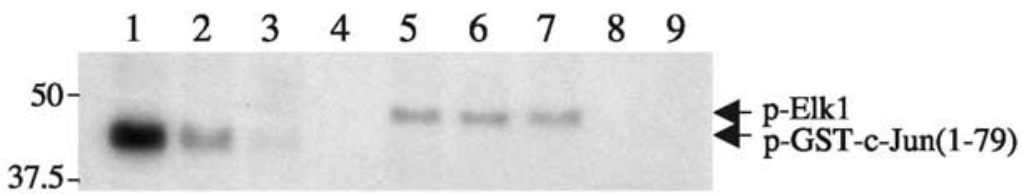

$37.5-$

$\begin{array}{llllllllll}+ & + & + & + & + & + & + & - & - & \text { Injured neuronal lysate } \\ + & + & + & - & - & - & - & + & - & \text { GST-c-Jun }(1-79) \\ - & - & - & - & + & + & + & - & + & \text { Elk1 } \\ - & 1 & 10 & - & - & 1 & 10 & - & - & \operatorname{SP} 600125(\mu \mathrm{M})\end{array}$

$\mathbf{E}$
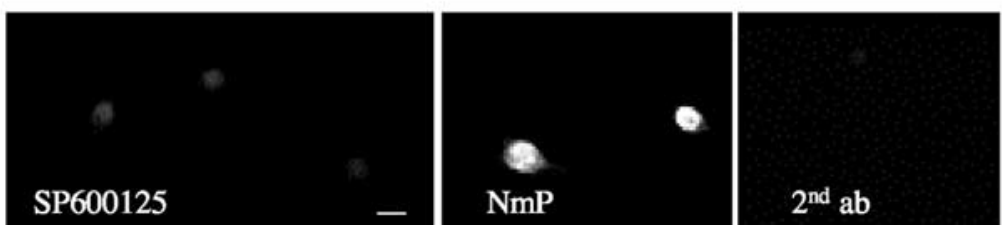

Figure 4. Cultured neurons express p73-c-Jun and AP1 transcriptional activity. $\boldsymbol{A}$, Representative confocal images from two experiments showing Ab-p-JNK (green, left) and Ab-p73-c-Jun (red, middle) immunofluorescence in $2 \mu \mathrm{m}$ optical sections through the nucleus of the sensory neurons on day 2 in vitro. B, AP1-dependent expression of a heterologous reporter protein (GFP) in injured cultured sensory neurons. pNEX-GFP or pNEXAP1-GFP plasmid DNA was injected into sensory neurons on day 1 in vitro (5 sensory neurons per plasmid). GFP expression was examined $16 \mathrm{~h}$ later by fluorescence microscopy. Fluorescence was only observed in pNEXAP1-GFP injected cells (20\% expression; $n=3$ experiments). C, Nuclear translocation of apJNK after axotomy in vitro. Representative images from two experiments showing p-apJNK immunofluorescence in the nucleus of sensory neurons after $7 \mathrm{~d}$ in vitro. The top row shows $2 \mu \mathrm{m}$ optical sections of control sensory neurons, and the bottom row shows sensory neurons that were axotomized 15 min before fixation. D, SP600125 inhibits the ability of apJNK to phosphorylate c-Jun. A total of $5 \mu \mathrm{g}$ of injured pleural ganglia extract was incubated with GST- - -Jun(1-79) or Elk1 in the presence or absence of SP600125 at the indicated concentrations. apJNK activity was assayed by the transfer of ${ }^{32} \mathrm{P}$ from $\left[\gamma_{-}{ }^{32} \mathrm{P}\right]$ ATP to GST - c-Jun(1-79) or Elk1 in vitro, followed by autoradiography. $\boldsymbol{E}$, Inhibiting axotomy-induced apJNK activation reduces the phosphorylation of c-Jun. The $4 \mathrm{~d}$ sensory neurons were axotomized in the presence of $1 \mu \mathrm{m}$ SP600125 or its nonactive form, NmP, and were placed in vitro in the continued presence of the drugs. At $1 \mathrm{~d}$ later, the cells were fixed and exposed to Ab-p73-c-Jun to detect p73-c-Jun in the nucleus. 


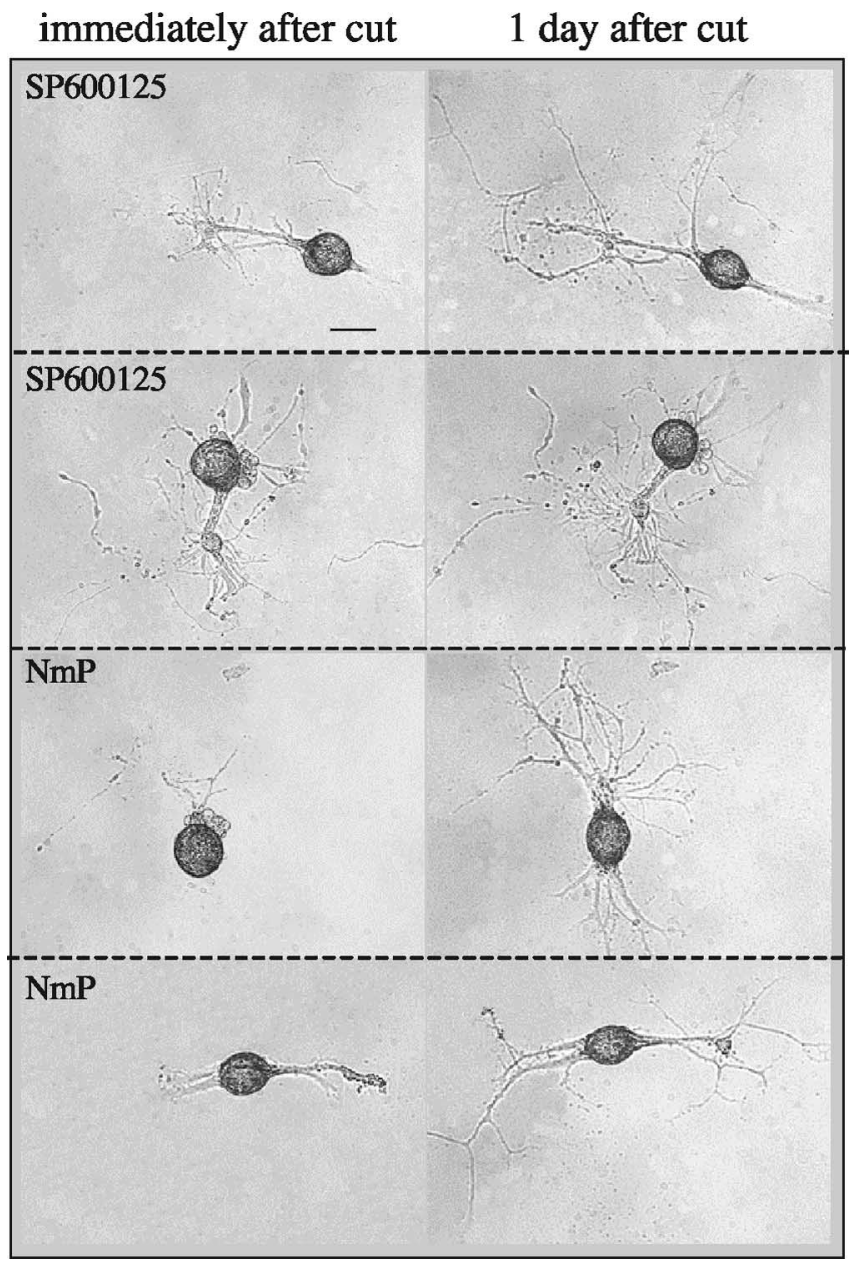

Figure 5. Inhibiting axotomy-induced apJNK activation does not affect neurite outgrowth Photomicrographs of $4 \mathrm{~d}$ cultured sensory neurons immediately after transection (left) and $24 \mathrm{~h}$ after axotomy (right) in the presence of drugs. Two examples of each treatment are shown. Scale bar, $50 \mu \mathrm{m}$.

1994; $\mathrm{Hu}$ et al., 2004). We therefore assessed the state of the apJNK-c-Jun pathway during the formation of these synapses. Cultures were prepared in medium containing either SP600125 or NmP. Cocultures consisted of one or two sensory neurons with one L7. The strength of the synaptic connections was determined $2 \mathrm{~d}$ later by stimulating the sensory neurons and measuring the EPSPs in L7. The amplitude of the EPSPs in the presence of the active inhibitor was significantly greater than that in the control ( $p<0.0001$ by ANOVA and Newman-Keuls test) (Fig. $7 A)$. The cells were then fixed and immunostained with antip73-c-Jun antibody. Significantly less p73-c-Jun was present in the sensory neurons exposed to the inhibitor (Fig. $7 B$ ). In contrast, the level of p73-c-Jun in L7 was very low compared with sensory neurons, and its expression was not affected by SP600126 treatment (Fig. 7B). Moreover, the level of p73-c-Jun in sensory neurons was found to correlate directly with the size of the EPSPs $(p=0.0035)$ (Fig. 7B). Thus, for each neuron, a strong EPSP was associated with a low p73-c-Jun level in the nucleus and vice versa. These data indicate that the reduction in apJNK-c-Jun activity is linked to synaptogenesis.

\section{Discussion}

Studies of axon regeneration have shown that the levels of certain mRNAs increase during axotomy, remain elevated for long peri- ods, and then decrease when the regenerating axons contact their targets (Lin et al., 2003; Colby et al., 2005a). Relatively little is known about how transcription is regulated after axotomy. The AP1 transcriptional complex is likely to be important because it remains active in rats long after axotomy (Kenney and Kocsis, 1998) and is activated by JNK retrogradely transported from the site of injury (Lindwall and Kanje, 2005). We first evaluated AP1 DNA binding activity in Aplysia sensory neurons and found that it behaved like its vertebrate counterpart: it was activated after nerve crush via the JNK-c-Jun pathway, and the level of binding activity persisted until regeneration was complete. We then examined several essential sequelae to axotomy and found that the Aplysia AP1 does not contribute to a long-term event, such as growth, but that it is regulated by synaptogenesis with specific targets.

\section{The persistent activation of the AP1 after axotomy occurs via} a conserved pathway involving apJNK and c-Jun

Crushing Aplysia peripheral nerves in vivo resulted in the persistent binding of an AP1 transcription complex to a consensus TRE enhancer site in injured pleural neurons (Fig. 1C). The formation of the AP1 complex required an axotomy-induced phosphorylation of the conserved -T-P-Y- domain in apJNK, which both activates the kinase and promotes its translocation into the nucleus (Fig. 4C). Vertebrate p-JNK phosphorylates c-Jun Ser-73, resulting in its activation (Pulverer et al., 1991; Smeal et al., 1991, 1994), and we found apJNK and c-Jun in the nucleus of the sensory neurons after axotomy (Figs. 2C, 4A).

Three lines of evidence show that apJNK activates c-Jun. First, recombinant active apJNK phosphorylated Ser-73 on c-Jun (Fig. $3 D, E)$. Second, p73-c-Jun and p-apJNK are present together in the nucleus when the AP1 is active (Fig. 4A,B). Third, inhibiting apJNK activation greatly reduced p73-c-Jun immunostaining (Fig. $4 E$ ). Thus, we expected that the JNK-c-Jun-AP1 pathway in axotomized sensory neurons in Aplysia would mediate some of the same functions described in injured vertebrate neurons.

\section{The JNK-c-Jun-AP1 pathway does not activate apoptosis, regulate growth, or induce $\mathrm{LTH}$ in the sensory neurons after axotomy}

The JNK-Jun-AP1 pathway is believed to regulate apoptosis in some neurons after nerve injury (Ham et al., 2000; Herdegen and Waetzig, 2001; Shaulian and Karin, 2002). Crushing peripheral nerves axotomizes Aplysia sensory neuron axons (Dulin et al., 1995; Steffensen et al., 1995), resulting in regenerative growth and an LTH that lasts for weeks (Billy and Walters, 1989; Walters et al., 1991; Clatworthy and Walters, 1994; Bedi et al., 1998). Because c-Jun-AP1 activities are sustained throughout (Figs. 1C, $2 C)$, it was unlikely that AP1 influenced survival, and we found that almost all of the sensory neurons were viable 4 weeks after nerve crush (supplemental Fig. 1, available at www.jneurosci.org as supplemental material). The absence of a correlation between apoptosis in sensory neurons and their AP1 activity is consistent with some studies from vertebrates (Herdegen et al., 1993; Brecht et al., 1997; Colby et al., 2005b).

A much stronger argument could be made for a role of the AP1 complex in neurite growth by sensory neurons. Expression of p-JNK and p73-c-Jun was high during the period of robust growth (day 2 in culture) (Fig. $4 A$ ) and relatively low when growth slowed (day 7 in culture) (Fig. 4C). This relatively low staining is reversed by additional axotomy of sensory neurons, which induces new growth (Fig. 4C,E). Each axotomy of the sensory neuron resulted in new growth, the translocation of p-JNK 
$\mathbf{A}$

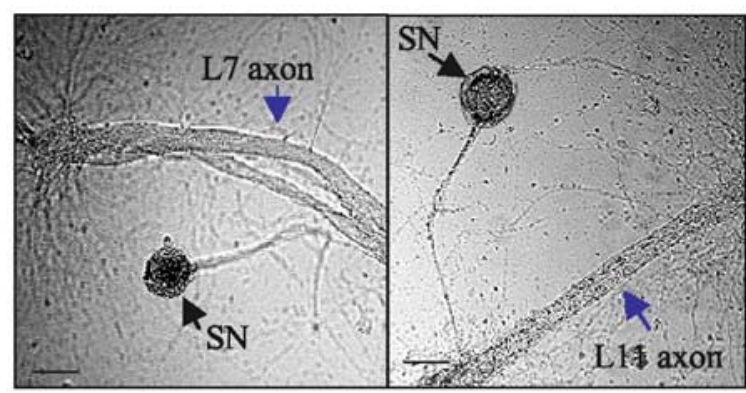

B

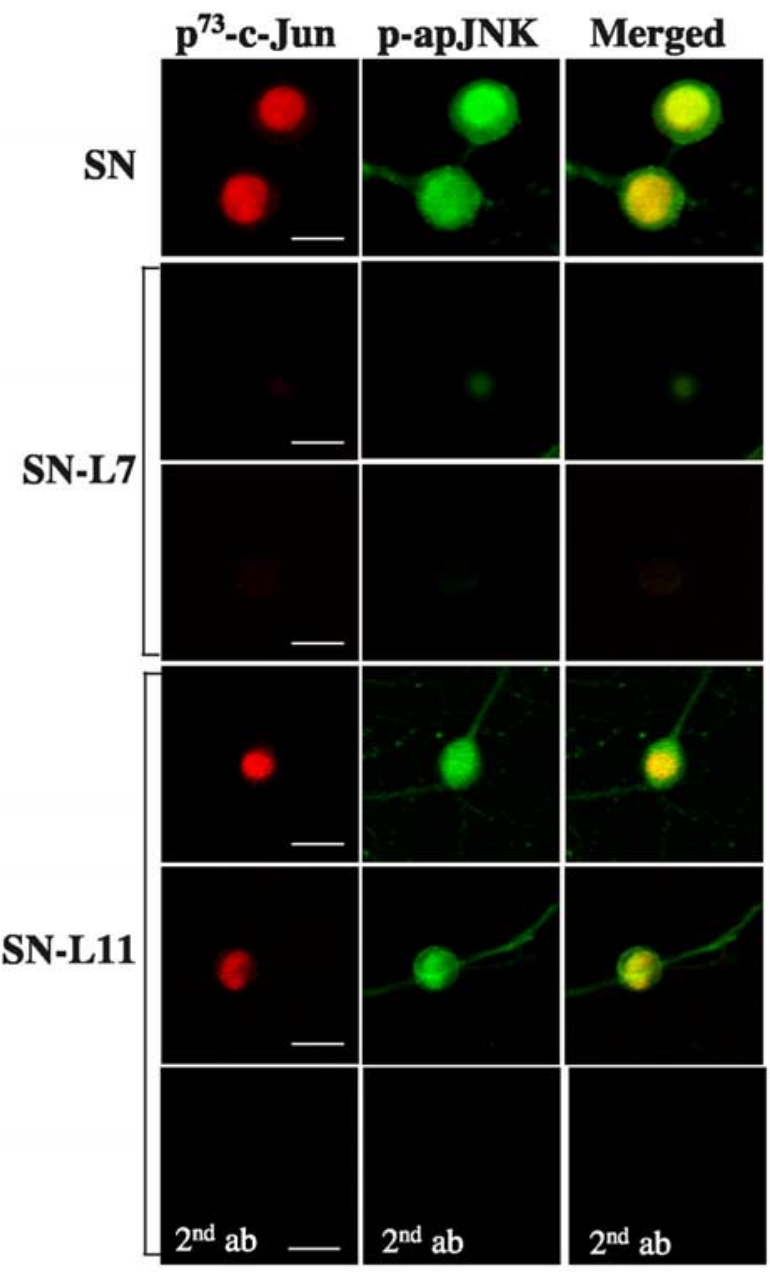

C

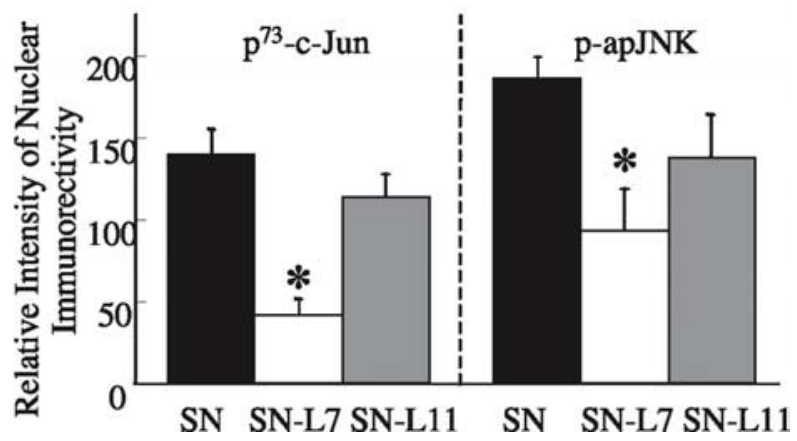

Figure 6. $\quad \boldsymbol{A}$, Photomicrographs of $4 \mathrm{~d}$ sensory neuron (SN)-L7 (left) and SN-L11 (right) cocultures near the contact point between the major axons and the sensory neuron arbor. Individual cells marked by colored arrows: SN, black; L7-L11, blue. Scale bar, $50 \mu \mathrm{m}$. B, Decrease in p73-c-Jun and p-apJNK activity in sensory neurons after contact with L7. SN-SN, $\mathrm{SN}-\mathrm{L} 7$, and SN-L11 cocultures were fixed on day 4 and then immunostained for p73-c-Jun (red, left) and p-apJNK (green, middle). Top five rows, Representative examples of SN-SN, into the nucleus (Fig. 4C), and the phosphorylation of c-Jun (Fig. $4 A)$. Nevertheless, reducing the injury-induced c-Jun phosphorylation by inhibiting apJNK activity with SP600125 (Fig. 4D,E) had no effect on neurite outgrowth in the sensory neurons (Fig. 5). Although others have implicated JNK in growth (Yao et al., 1997; Waetzig and Herdegen, 2003; Eom et al., 2005), our findings suggest that, in a single defined population of sensory neurons, this pathway does not significantly influence neurite growth per se. Other classes of neurons might respond differently. Support for this idea comes from the sensory neuron-L7 cocultures in which changes in apJNK activity is detected in the sensory neurons but not in L7 (Fig. 7B).

We also found that the apJNK-c-Jun pathway does not regulate LTH, which appears in both Aplysia sensory neurons and some vertebrate primary sensory neurons after axotomy (Sung et al., 2004). Inhibiting the pathway with SP600125 did not affect axotomy-induced changes in excitability or other electrical properties in the sensory neurons.

The findings that the JNK-c-Jun-AP1 pathway does not regulate apoptosis, growth, or LTH in axotomized Aplysia sensory neurons might be explained by several important differences compared with the pathway that is activated in some injured vertebrate neurons. First, only a single JNK isoform appears to be expressed in Aplysia sensory neurons to mediate the response to injury, whereas vertebrate neurons contain multiple JNK isoforms (Davis, 2000; Weston and Davis, 2002). Thus, Ab-p-JNK (which binds a conserved activation domain in the protein) recognizes JNK1 and JNK2 in rats but recognized only a single band on Western blots of Aplysia neuronal proteins (Fig. 3B). Second, vertebrate p73-c-Jun dimerizes with members of the ATF and Jun subfamilies (Shaulian and Karin, 2002) to form complexes that bind to both TRE and CRE sequences (Herdegen and Leah, 1998; Chinenov and Kerppola, 2001). However, the AP1 transcriptional complex formed in the sensory neurons after nerve injury comprises p73-c-Jun homodimers (Fig. 2A) that bind exclusively to TRE enhancers (Fig. $1 B$ ). Third, ATF-2 can also be activated by JNK in vertebrate neurons (Herdegen et al., 1997; Herdegen and Waetzig, 2001), but we found that ATF-2 is not activated in the sensory neurons by injury (Fig. $2 \mathrm{~A}$ ). This relative simplicity will facilitate future studies on the regulation of the AP1.

\section{p-JNK and c-Jun are inactivated during synaptic contact}

Our finding of a reduction in AP1 DNA-binding activity in vivo at a time when functional connections were restored (Fig. 1C) pointed to a role for the AP1 in the final stage of regeneration. Studies in Drosophila have implicated the AP1 in regulating bouton number and synaptic strength (Sanyal et al., 2002), and facial nerve target reinnervation is impaired in c-Jun knock-out mice (Raivich et al., 2004). To determine the response of the AP1 to synapse formation, we took advantage of previous studies showing that sensory neurons readily form synapses in vitro on motor neuron L7 but not on neuron L11 (Glanzman et al., 1989; Dale and Kandel, 1993; Lin and Glanzman, 1994; Zhu et al., 1997;

\section{$\leftarrow$}

SN-L7, and SN-L11 cultures. Bottom row, Secondary antibody control. Each image is a $2 \mu \mathrm{m}$ optical section through the sensory cell body to show the nucleus. Scale bar, $50 \mu \mathrm{m}$. C, Histogram of the Mean \pm SEM staining intensity of SN nuclear p73-c-Jun and p-apJNK immunoreactivity from three separate experiments. The number of cells in the $\mathrm{SN}$ (black bar), $\mathrm{SN}-\mathrm{L} 7$ (blank bar), and SN-L11 (gray bar) groups are 12, 10, and 8, respectively. The asterisks indicate that the $\mathrm{SN}-\mathrm{L} 7$ data are significantly different from sensory neurons alone and $\mathrm{SN}-\mathrm{L} 11$ cocultures as described in Results. 


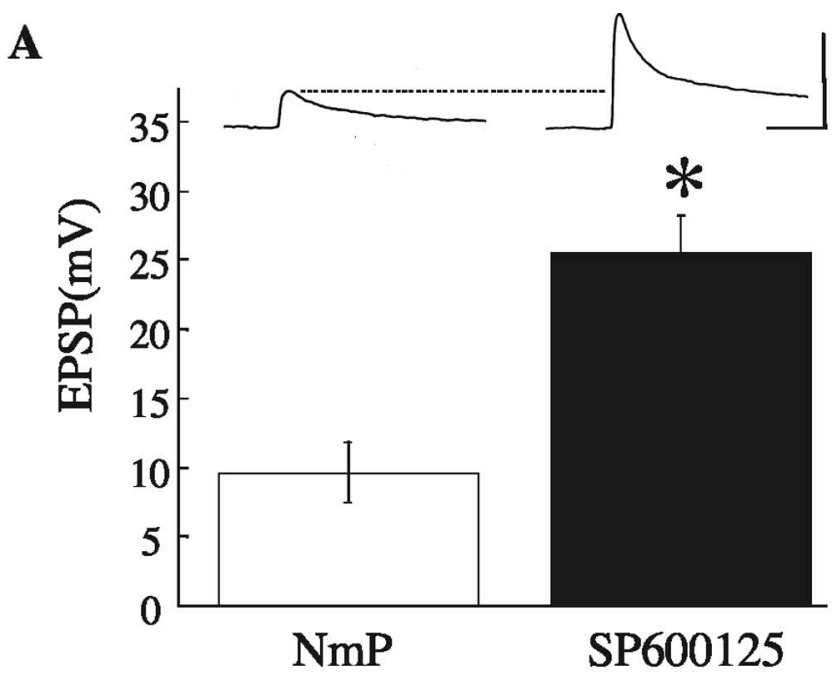

B
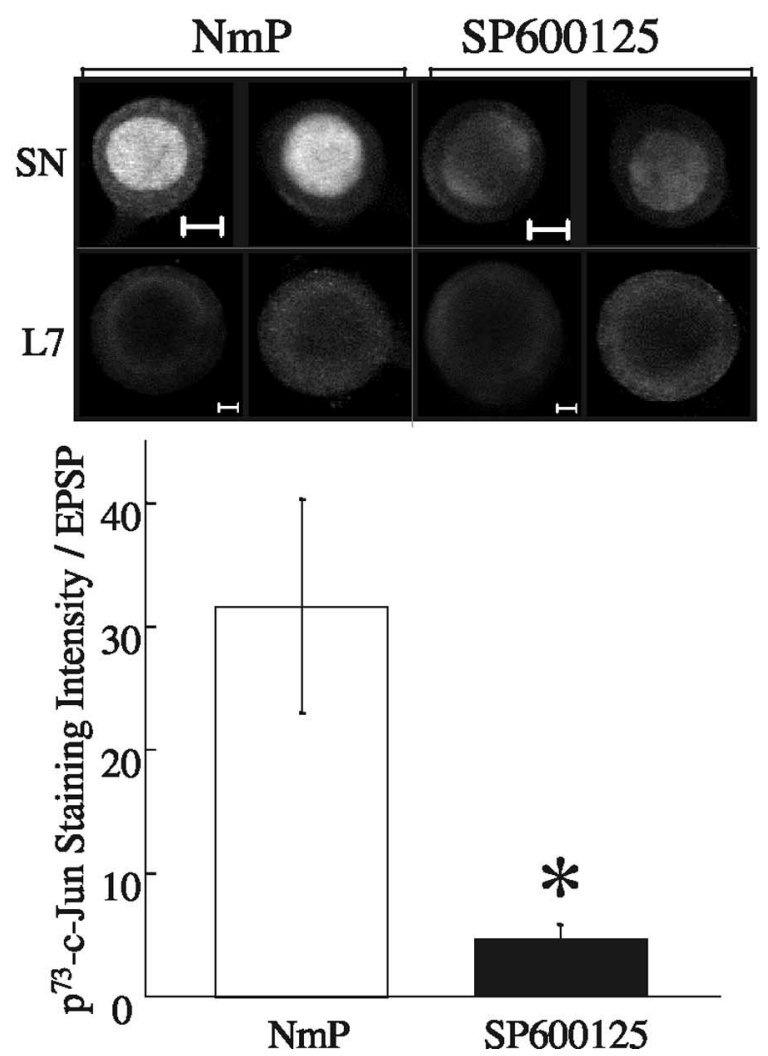

Figure 7. Inhibiting JNK activity increases synaptic activity. L7 and sensory neuron were cocultured in the presence of $1 \mu \mathrm{M}$ SP600125 or NmP. EPSPs were recorded on day 2. A, Top, Representative EPSPs recorded in L7. SP600125 treatment increased the amplitude of EPSPs when compared with NmP treatment. Calibration: $25 \mathrm{~ms}, 25 \mathrm{mV}$. Bottom, Summary of the effect of SP600125 on EPSP amplitudes. Error bars indicate SEM; ${ }^{*} p<0.0001$. $\boldsymbol{B}$, Representative examples of $\mathrm{p} 73-\mathrm{c}$-Jun expression in cocultured sensory neuron $(\mathrm{SN})$ and $\mathrm{L} 7$ in the presence of NmP or SP600125 from three separate experiments. SN-L7 cocultures were fixed immediately after EPSP recording and then immunostained for p73-c-Jun. Each image is a $2 \mu \mathrm{m}$ optical section through the sensory cell body to show the nucleus. Scale bar, $20 \mu \mathrm{m}$. The histogram shows the ratio of nuclear p73- $c$-Jun staining intensity/EPSP in SN cells treated with $\mathrm{NmP}$ (white bar) or SP600125 (black bars). A total of 20 SNs were assessed under each condition $(p<0.0035$, Scheffé's test).
Armitage and Siegelbaum, 1998; Schacher et al., 1999). We found a significant reduction in the level of p-apJNK and p73-c-Jun in the nucleus of sensory neurons in contact with L7 relative to sensory neurons contacting L11 or to sensory neurons grown alone (Fig. 6). Because sensory neuron growth is enhanced when contacting L7 compared with L11 (Glanzman et al., 1989; Schacher and Montarolo, 1991), these findings are most readily explained by a synapse-dependent inactivation of the apJNKc-Jun-AP1 pathway.

If the pathway is associated with synaptogenesis, then inhibiting the apJNK-c-Jun pathway with JNK inhibitor SP600125 as synapses develop should enhance or accelerate synaptogenesis. To test this idea, we looked for an inverse relationship between the level of AP1 activity and the strength of the developing synapse. Synaptic connections between sensory neurons and L7 can be detected within $16 \mathrm{~h}$ after placing the cells in culture, but the connections continue to mature and strengthen until day 4 . Exposing sensory neuron-L7 cocultures during the first $48 \mathrm{~h}$ to the JNK inhibitor increased synaptic strength (Fig. 7A), and this increase correlated directly with reduced levels of p-c-Jun in the nucleus of the sensory neurons (Fig. 7B). We believe that this effect is likely attributable to the specific inhibition of JNK by SP600125. The induction of LTH, neurite outgrowth, and synapse formation collectively require the activation of kinases such as protein kinase G, MAPK, protein kinase A, protein kinase $\mathrm{C}$, and calcium/calmodulin-dependent kinase II, to name a few, yet none of these complex processes was affected by the SP600125. Nevertheless, to fully examine the role JNK plays in synaptogenesis will require the development of additional tools. Vertebrate JNK exists as three related proteins (JNK1, JNK2, and JNK3), and alternative splicing results in at least 10 different variant proteins (Waetzig and Herdegen, 2004), which are broadly and differentially distributed in various cells and tissues (Waetzig and Herdegen, 2005). Because SP600125 inhibits all of these isoforms, it will be necessary to develop inducible transgenic knock-outs of each isoform to determine which JNK isoform is involved in synaptogenesis and regeneration at the periphery in vivo. In addition, future studies should be designed to determine the effect JNK-c-Jun complex formation has on fully formed stable synapses. This will provide important insights into the role of the complex in regulating synaptic homeostasis.

Our data indicate that a target-mediated downregulation of p73-c-Jun and apJNK influences the rate of new synapse formation. This is consistent with the idea that the JNK-Jun-AP1 pathway links the sensory neuron synapse to the cell nucleus. Thus, the pathway is activated when communication with the follower neuron is lost and is inactivated when the communication is restored. Furthermore, the activation of the pathway seems to be cell specific because p73-c-Jun expression in L7 is relatively low during the period and is not affected significantly by the inhibitors (Fig. $7 B$ ). Synaptogenesis begins with the contact of an axon with its target. In turn, this stimulates processes that can stabilize and mature that contact into a synapse. Thus, the presynaptic and postsynaptic elements must recognize one another as appropriate partners and then undergo a sequence of transformations of their local morphology and molecular components. We speculate that, once the initial synaptic contact is established between the sensory neuron and appropriate target cell, it triggers the activation of phosphatases to dephosphorylate p73-c-Jun and/or p-apJNK (Alberts et al., 1993; Al-Murrani et al., 1999) or evokes protein degradation via the ubiquitin proteasome pathway (Musti et al., 1997; Nateri et al., 2004). The effect is to release inhibitory influences on the transcription of mRNAs that promote synaptogen- 
esis. Future studies are required to elucidate the identity of the stop signals and also to address whether it is controlled by a presynaptic mechanism alone or by retrograde signals from the postsynaptic neuron.

\section{References}

Alberts AS, Deng T, Lin A, Meinkoth JL, Schonthal A, Mumby MC, Karin M, Feramisco JR (1993) Protein phosphatase 2A potentiates activity of promoters containing AP-1-binding elements. Mol Cell Biol 13:2104-2112.

Al-Murrani SW, Woodgett JR, Damuni Z (1999) Expression of I2PP2A, an inhibitor of protein phosphatase $2 \mathrm{~A}$, induces c-Jun and AP-1 activity. Biochem J 341:293-298.

Ambron RT, Walters ET (1996) Priming events and retrograde injury signals. A new perspective on the cellular and molecular biology of nerve regeneration. Mol Neurobiol 13:61-79.

Ambron RT, Zhang XP, Gunstream JD, Povelones M, Walters ET (1996) Intrinsic injury signals enhance growth, survival, and excitability of Aplysia neurons. J Neurosci 16:7469-7477.

Armitage BA, Siegelbaum SA (1998) Presynaptic induction and expression of homosynaptic depression at Aplysia sensorimotor neuron synapses. J Neurosci 18:8770-8779.

Bedi SS, Salim A, Chen S, Glanzman DL (1998) Long-term effects of axotomy on excitability and growth of isolated Aplysia sensory neurons in cell culture: potential role of cAMP. J Neurophysiol 79:1371-1383.

Billy AJ, Walters ET (1989) Long-term expansion and sensitization of mechanosensory receptive fields in Aplysia support an activity-dependent model of whole-cell sensory plasticity. J Neurosci 9:1254-1262.

Brecht S, Buschmann T, Grimm S, Zimmermann M, Herdegen T (1997) Persisting expression of galanin in axotomized mammillary and septal neurons of adult rats labeled for c-Jun and NADPH-diaphorase. Brain Res Mol Brain Res 48:7-16.

Chin J, Angers A, Cleary LJ, Eskin A, Byrne JH (2002) Transforming growth factor $\beta 1$ alters synapsin distribution and modulates synaptic depression in Aplysia. J Neurosci 22:RC220(1-6).

Chinenov Y, Kerppola TK (2001) Close encounters of many kinds: Fos-Jun interactions that mediate transcription regulatory specificity. Oncogene 20:2438-2452.

Clatworthy AL, Walters ET (1994) Comparative analysis of hyperexcitability and synaptic facilitation induced by nerve injury in two populations of mechanosensory neurones of Aplysia californica. J Exp Biol 190:217-238.

Colby GP, Sung YJ, Ambron RT (2005a) mRNAs encoding the Aplysia homologues of fasciclin-I and b-thymosin are expressed only in the second phase of nerve injury and are differentially segregated in axons regenerating in vitro and in vivo. J Neurosci Res 82:484-498.

Colby GP, Coon AL, Connolly Jr ES, Ambron RT (2005b) Activation of c-Jun and ATF-2 in primate motor cranial nerve nuclei is not associated with apoptosis following axotomy. Exp Neurol 194:57-65.

Dale N, Kandel ER (1993) L-glutamate may be the fast excitatory transmitter of Aplysia sensory neurons. Proc Natl Acad Sci USA 90:7163-7167.

Dale N, Schacher S, Kandel ER (1988) Long-term facilitation in Aplysia involves increase in transmitter release. Science 239:282-285.

Davis RJ (2000) Signal transduction by the JNK group of MAP kinases. Cell 103:239-252.

Derijard B, Hibi M, Wu IH, Barrett T, Su B, Deng T, Karin M, Davis RJ (1994) JNK1: a protein kinase stimulated by UV light and Ha-Ras that binds and phosphorylates the c-Jun activation domain. Cell 76:1025-1037.

Dulin MF, Steffensen I, Morris CE, Walters ET (1995) Recovery of function, peripheral sensitization and sensory neurone activation by novel pathways following axonal injury in Aplysia californica. J Exp Biol 198:2055-2066.

Eom DS, Choi WS, Ji S, Cho JW, Oh YJ (2005) Activation of c-Jun $\mathrm{N}$-terminal kinase is required for neurite outgrowth of dopaminergic neuronal cells. NeuroReport 16:823-828.

Farr M, Zhu DF, Povelones M, Valcich D, Ambron RT (2001) Direct interactions between immunocytes and neurons after axotomy in Aplysia. J Neurobiol 46:89-96.

Glanzman DL, Kandel ER, Schacher S (1989) Identified target motor neuron regulates neurite outgrowth and synapse formation of Aplysia sensory neurons in vitro. Neuron 3:441-450.

Glanzman DL, Kandel ER, Schacher S (1990) Target-dependent structural changes accompanying long-term synaptic facilitation in Aplysia neurons. Science 249:799-802.

Ham J, Eilers A, Whitfield J, Neame SJ, Shah B (2000) c-Jun and the transcriptional control of neuronal apoptosis. Biochem Pharmacol 60:1015-1021.

Herdegen T, Leah JD (1998) Inducible and constitutive transcription factors in the mammalian nervous system: control of gene expression by Jun, Fos and Krox, and CREB/ATF proteins. Brain Res Brain Res Rev 28:370-490.

Herdegen T, Waetzig V (2001) AP-1 proteins in the adult brain: facts and fiction about effectors of neuroprotection and neurodegeneration. Oncogene 20:2424-2437.

Herdegen T, Bastmeyer M, Bahr M, Stuermer C, Bravo R, Zimmermann M (1993) Expression of JUN, KROX, and CREB transcription factors in goldfish and rat retinal ganglion cells following optic nerve lesion is related to axonal sprouting. J Neurobiol 24:528-543.

Herdegen T, Blume A, Buschmann T, Georgakopoulos E, Winter C, Schmid W, Hsieh TF, Zimmermann M, Gass P (1997) Expression of activating transcription factor-2, serum response factor and cAMP/Ca response element binding protein in the adult rat brain following generalized seizures, nerve fibre lesion and ultraviolet irradiation. Neuroscience $81: 199-212$.

Hibi M, Lin A, Smeal T, Minden A, Karin M (1993) Identification of an oncoprotein- and UV-responsive protein kinase that binds and potentiates the c-Jun activation domain. Genes Dev 7:2135-2148.

Hu JY, Glickman L, Wu F, Schacher S (2004) Serotonin regulates the secretion and autocrine action of a neuropeptide to activate MAPK required for long-term facilitation in Aplysia. Neuron 43:373-385.

Kallunki T, Su B, Tsigelny I, Sluss HK, Derijard B, Moore G, Davis R, Karin M (1994) JNK2 contains a specificity-determining region responsible for efficient c-Jun binding and phosphorylation. Genes Dev 8:2996-3007.

Karin M, Liu Z, Zandi E (1997) AP-1 function and regulation. Curr Opin Cell Biol 9:240-246.

Kenney AM, Kocsis JD (1998) Peripheral axotomy induces long-term c-Jun amino-terminal kinase- 1 activation and activator protein- 1 binding activity by c-Jun and junD in adult rat dorsal root ganglia in vivo. J Neurosci 18:1318-1328.

Kyriakis JM, Banerjee P, Nikolakaki E, Dai T, Rubie EA, Ahmad MF, Avruch J, Woodgett JR (1994) The stress-activated protein kinase subfamily of c-Jun kinases. Nature 369:156-160.

Liao X, Gunstream JD, Lewin MR, Ambron RT, Walters ET (1999) Activation of protein kinase A contributes to the expression but not the induction of long-term hyperexcitability caused by axotomy of Aplysia sensory neurons. J Neurosci 19:1247-1256.

Lin A, Minden A, Martinetto H, Claret FX, Lange-Carter C, Mercurio F, Johnson GL, Karin M (1995) Identification of a dual specificity kinase that activates the Jun kinases and p38-Mpk2. Science 268:286-290.

Lin H, Bao J, Sung YJ, Walters ET, Ambron RT (2003) Rapid electrical and delayed molecular signals regulate the serum response element after nerve injury: convergence of injury and learning signals. J Neurobiol 57:204-220.

Lin XY, Glanzman DL (1994) Long-term potentiation of Aplysia sensorimotor synapses in cell culture: regulation by postsynaptic voltage. Proc $\mathrm{R}$ Soc Lond B Biol Sci 255:113-118.

Lindwall C, Kanje M (2005) Retrograde axonal transport of JNK signaling molecules influence injury induced nuclear changes in p-c-Jun and ATF3 in adult rat sensory neurons. Mol Cell Neurosci 29:269-282.

Martin KC, Casadio A, Zhu H, E Y, Rose JC, Chen M, Bailey CH, Kandel ER (1997) Synapse-specific, long-term facilitation of Aplysia sensory to motor synapses: a function for local protein synthesis in memory storage. Cell 91:927-938.

Montarolo PG, Goelet P, Castellucci VF, Morgan J, Kandel ER, Schacher S (1986) A critical period for macromolecular synthesis in long-term heterosynaptic facilitation in Aplysia. Science 234:1249-1254.

Mossman BT (1983) In vitro approaches for determining mechanisms of toxicity and carcinogenicity by asbestos in the gastrointestinal and respiratory tracts. Environ Health Perspect 53:155-161.

Musti AM, Treier M, Bohmann D (1997) Reduced ubiquitin-dependent degradation of c-Jun after phosphorylation by MAP kinases. Science 275:400-402.

Nateri AS, Riera-Sans L, Da Costa C, Behrens A (2004) The ubiquitin ligase SCFFbw7 antagonizes apoptotic JNK signaling. Science 303:1374-1378. 
Park S, Hahm ER, Lee DK, Yang CH (2004) Inhibition of AP-1 transcription activator induces myc-dependent apoptosis in HL60 cells. J Cell Biochem 91:973-986.

Pulverer BJ, Kyriakis JM, Avruch J, Nikolakaki E, Woodgett JR (1991) Phosphorylation of c-jun mediated by MAP kinases. Nature 353:670-674.

Raivich G, Bohatschek M, Da Costa C, Iwata O, Galiano M, Hristova M, Nateri AS, Makwana M, Riera-Sans L, Wolfer DP, Lipp HP, Aguzzi A, Wagner EF, Behrens A (2004) The AP-1 transcription factor c-Jun is required for efficient axonal regeneration. Neuron 43:57-67.

Rayport SG, Schacher S (1986) Synaptic plasticity in vitro: cell culture of identified Aplysia neurons mediating short-term habituation and sensitization. J Neurosci 6:759-763.

Sanyal S, Sandstrom DJ, Hoeffer CA, Ramaswami M (2002) AP-1 functions upstream of CREB to control synaptic plasticity in Drosophila. Nature 416:870-874.

Schacher S, Montarolo PG (1991) Target-dependent structural changes in sensory neurons of Aplysia accompany long-term heterosynaptic inhibition. Neuron 6:679-690.

Schacher S, Wu F, Panyko JD, Sun ZY, Wang D (1999) Expression and branch-specific export of mRNA are regulated by synapse formation and interaction with specific postsynaptic targets. J Neurosci 19:6338-6347.

Shaulian E, Karin M (2002) AP-1 as a regulator of cell life and death. Nat Cell Biol 4:E131-E136.

Shin M, Yan C, Boyd D (2002) An inhibitor of c-jun aminoterminal kinase (SP600125) represses c-Jun activation, DNA-binding and PMA-inducible 92-kDa type IV collagenase expression. Biochim Biophys Acta 1589:311-316.

Smeal T, Binetruy B, Mercola DA, Birrer M, Karin M (1991) Oncogenic and transcriptional cooperation with $\mathrm{Ha}$-Ras requires phosphorylation of c-Jun on serines 63 and 73. Nature 354:494-496.

Smeal T, Hibi M, Karin M (1994) Altering the specificity of signal transduction cascades: positive regulation of c-Jun transcriptional activity by protein kinase A. EMBO J 13:6006-6010.

Steffensen I, Dulin MF, Walters ET, Morris CE (1995) Peripheral regeneration and central sprouting of sensory neurone axons in Aplysia californica following nerve injury. J Exp Biol 198:2067-2078.

Sun ZY, Schacher S (1996) Tetanic stimulation and cyclic adenosine monophosphate regulate segregation of presynaptic inputs on a common postsynaptic target neuron in vitro. J Neurobiol 29:183-201.

Sung YJ, Ambron RT (2004) Pathways that elicit long-term changes in gene expression in nociceptive neurons following nerve injury: contributions to neuropathic pain. Neurol Res 26:195-203.

Sung YJ, Conti J, Currie JR, Brown WT, Denman RB (2000) RNAs that interact with the fragile $\mathrm{X}$ syndrome RNA binding protein FMRP. Biochem Biophys Res Commun 275:973-980.

Sung YJ, Povelones M, Ambron RT (2001) RISK-1: a novel MAPK homologue in axoplasm that is activated and retrogradely transported after nerve injury. J Neurobiol 47:67-79.

Sung YJ, Walters ET, Ambron RT (2004) A neuronal isoform of protein kinase $\mathrm{G}$ couples mitogen-activated protein kinase nuclear import to axotomy-induced long-term hyperexcitability in Aplysia sensory neurons. J Neurosci 24:7583-7595.

Tanaka S, Suzuki K, Watanabe M, Matsuda A, Tone S, Koike T (1998) Upregulation of a new microglial gene, mrf-1, in response to programmed neuronal cell death and degeneration. J Neurosci 18:6358-6369.

Waetzig V, Herdegen T (2003) The concerted signaling of ERK1/2 and JNKs is essential for PC12 cell neuritogenesis and converges at the level of target proteins. Mol Cell Neurosci 24:238-249.

Waetzig V, Herdegen T (2004) Neurodegenerative and physiological actions of c-Jun N-terminal kinases in the mammalian brain. Neurosci Lett 361:64-67.

Waetzig V, Herdegen T (2005) Context-specific inhibition of JNKs: overcoming the dilemma of protection and damage. Trends Pharmacol Sci 26:455-461.

Walters ET, Alizadeh H, Castro GA (1991) Similar neuronal alterations induced by axonal injury and learning in Aplysia. Science 253:797-799.

Weston CR, Davis RJ (2002) The JNK signal transduction pathway. Curr Opin Genet Dev 12:14-21.

Yao R, Yoshihara M, Osada H (1997) Specific activation of a c-Jun NH2terminal kinase isoform and induction of neurite outgrowth in PC-12 cells by staurosporine. J Biol Chem 272:18261-18266.

Zhu H, Wu F, Schacher S (1994) Aplysia cell adhesion molecules and serotonin regulate sensory cell- motor cell interactions during early stages of synapse formation in vitro. J Neurosci 14:6886-6900.

Zhu H, Wu F, Schacher S (1997) Site-specific and sensory neurondependent increases in postsynaptic glutamate sensitivity accompany serotonin-induced long-term facilitation at Aplysia sensorimotor synapses. J Neurosci 17:4976-4986.

Zimmermann M (2001) Pathobiology of neuropathic pain. Eur J Pharmacol 429:23-37. 